\section{SEVEN UNERUPTED TEETH IN THE SUPERIOR MAXILLA}

\section{E. P. R. RYAN, D.D.S. NEW YORK}

That foci of infection in systemic and general septic conditions are found in the mouth, in abscessed teeth and infected gum tissue, has been widely accepted by the profession. Actual pus-forming conditions of these organs, however, does not exclude them as a cause of systemic disorders. Pressure from teeth, dislodged from their normal tract, and the deposition of supernumerary teeth, are, in many baffling conditions, the unseen causes of chronic neuralgia, rhinitis, neuritis, nasal conditions and hysteria. I do not presume to offer this as a frequent or common cause in these conditions, but only to present it for consideration when other correct diagnosis cannot be reached.

Supernumerary teeth are much more common than we have hitherto believed, because we had no means of knowing their existence without the use of the roentgenograph. The daily use of the Roentgen ray in my practice has proved the truth of this statement by

\section{REPORT OF CASE}

This case, with the operation, is reported because it appears to be at least unique in that several teeth were found and removed:

Mrs. X, aged 34, consulted me concerning a bridge extending from the left lateral incisor tooth supplying the left central to the right central. She asked whether the teeth crowned could be in any way associated with the fistula draining into the right nostril. Examination was made of the bridge, and also the fistula observed; the septum was deflected entirely, closing the opening on the right side. A roentgenogram was immediately made through the anterior teeth, which showed an abscess on the left lateral incisor, and also a foreign formation near its apex. A larger film was used and a second exposure made with the tube pointing through and above the nose (Fig. 1). In this roentgenogram a large tooth will be seen which, according to the patient's history, was judged to be the unerupted central incisor, which had never appeared.

The following history was secured from the patient: The sore or sinus in the nose had been extremely annoying, breaking and running with bloody fluid, four or five times a day. She could not breathe through either nostril, and had not done so for about eight years. Each time, following the discharge of the fistula, she became very nervous, suffering from intense pain or pressure in the upper portion of her face, until she had become an extremely hysterical patient. This pressure was also noticed in her efforts at placing her tones high in her head while singing, and when forcing tones she imagined something moved in her head, so that she was compelled to give up her vocal efforts. Six years ago, the patient collapsed and remained unconscious for two days. She states that her case was diagnosed as nervous prostration, and that she never fully recovered from this attack. Two years ago, while dancing, she had felt an extreme pressure in the upper part of her face and again collapsed, this time remaining in a comatose condition for six days. She states the diagnosis was a "blood clot on the brain." She has been in a serious nervous condition since with periodic headaches, following a feeling of
Fig. 1.-Appearance of nest of teeth and large tooth. (Roeritgenogram by Ream.)
Fig. 2.-Appearance after removal of all teeth. (Roentgenogram by the author.) revealing many impacted and unerupted teeth which were direct causes of nerve pressure. We must realize that there are few normal mouths, that is, mouths in which all the teeth have erupted in proper occlusion, and that the tooth germ cells will deposit in any part of the body to which they may become deflected. A striking feature of the cases recorded in which teeth have been found in the nasal cavity is that only one or two teeth have been found, and in several cases the discovery of the tooth has been made when the patient has shown a tuberculous or syphilitic history.

Hopple $^{1}$ has reported a case of atrophic rhinitis in which the patient was treated for certain periods, and eventually a tooth was forced through the floor of the nose. Joachim ${ }^{2}$ reports a case in which the patient was treated for specific ulceration of the nasal septum, and a tooth was found in the floor of the nose.

The delay in the healing of the fistula leading from these teeth, in specific cases is recorded by Ingersoll. ${ }^{3}$ Removal of the cause is not always followed by immediate closing of the sinus.

1. Hopple: Brooklyn Med. Your., 1900, xiv, 403.

2. Joachim: Orleans Parish Med. Soc., 1895, iii, 52

3. Ingersoll: Laryngoscope, 1903, xiii, 688. pressure and the breaking of the fistula in the right nostril.
Dr. W. H. Haskin was consulted, and the diagnosis verified with the opinion that the tooth highest in the nose was deflecting the septum to the side, and causing the points of inflammation in the right nostril.

No tuberculin or Wassermann test was made.

The operation was performed in my office with Dr. W. V. Ryan assisting. Novocain and epinephrin was the anesthetic used, with infra-orbital, tuberosity and palacine injections.

The left lateral root was removed, and the incision over the apex carried to the base of the nose, with removal of bony tissue, by the use of the chisel and proper dental engine drills and burrs, exposing the nest of six supernumerary teeth. Considerable force and care was required in their removal, as they were packed against each other tightly and embedded in the bony tissue.

The patient's breathing was difficult, and after the removal of these teeth, a very pronounced dilatation of the nostril was noticed, and she exclaimed about "a wonderful breath of air." The only pain experienced during this operation was in her right ear, which was intense when pressure was placed on these teeth. The nervous condition of the patient prevented further operating, and the wound was packed for ten days.

A more profound anesthesia was secured for the next operation, and an injection made into the nasal cavity. With much difficulty and cutting of adhesive and bony tissue, the large unerupted central incisor tooth was exposed and found to be 
firmly embedded. By the use of the engine drill and chisel, it was cut off at the incisal edge and carefully worked down until it could be turned into the wound, in order to avoid splitting the surrounding bony tissue. The illustration of the tooth (Fig. 3), therefore, does not show its full length; but it was a perfectly formed central incisor.

A minimum amount of tissue was destroyed, and after the wound was healed, no depression was apparent from the outside and only a small evidence over the teeth in the mouth.

One month after the operation, the headaches and neuralgia had ceased, the hysterical condition was much improved, and the breathing was normal through the nose. The sinus in the nose, as in some cases quoted, was slow to heal; however, the bleeding appeared only occasionally.

A removable bridge was placed in the mouth to restore the lost central and lateral, and the patient was dismissed.

The pressure of these supernumerary teeth as well as the central incisor, forcing the septum, will be realized when the curve of the larger of the extra teeth is noted in Figure 3 . The three small teeth are wrapped around each other.

\section{CONCLUSION}

I believe that this case is an appeal for all who are treating the mouth, nose and surrounding parts to forestall any chance of error by the use of the roentgenograph. The surgeon may relieve many cases of difficult diagnosis, and every dentist who treats the roots of teeth should not work without the daily use of the roentgenograph.

452 Fifth Avenue.

\section{ORTHOPEDIC TREATMENT IN HEMIPLE- GICS OF LONG STANDING *}

GEORGE R. ELLIOTT, M.D.

Assistant Professor of Clinical Orthopedic Surgery, Columbia University, College of Physicians and Surgeons; Attending Orthopedic Surgeon, Montefiore Home and Hospital AND

SAMUEL W. BOORSTEIN, M.D.

Instructor in Orthopedic Surgery, Fordham University, School of Medicine; Adjunct Attending Orthopedic Surgeon, Montefiore Home and Hospital NEW YORK

It is generally accepted that if a hemiplegic has not improved within a short time, he will never improve; on the contrary, contractures will develop. These patients usually become chronic invalids. It will be of interest, therefore, to see what orthopedic treatment in old and neglected cases can do. This is a plea that the orthopedic treatments should be started early. Patient work will bring excellent results.

The prognosis which the attending physician usually gives to the patient is influenced by the teachings of the neurologists which is as follows: ${ }^{1}$

Patient recovers the power of walking in a short time, viz., six to eight weeks, but muscle retraction and shortening (contractures) almost invariably occur. . . . The depth

* Read in part before the Orthopedic Section, Academy of Medicine, Nov. 19,1915

1. Oppenheim, Hermann: Text Book of Nervous Diseases, Edinburgh, Otto Schultze \& Co., 1911, ii, 792. and duration of the apoplectic seizure will give some hint to the progress in the future. The more incomplete the apoplexy, the better are the chances for recovery. The course during the first few weeks will decide this point. If, during the first month, the hemiplegia continues unchanged in intensity or if only a trace of movement sets in in the affected limb, it will improve very little. On the other hand, a certain degree of movement setting in during the first few days, and steadily advancing during the first period, is a very favorable sign. . . . As soon, however, as the first evidence of contracture sets in there is hardly any prospect of complete restoration.

Dana, ${ }^{2}$ Church and Peterson ${ }^{3}$ and Starr, ${ }^{4}$ in their textbooks, state that after two years, no further gain is to be expected. Curschmann ${ }^{5}$ is of similar opinion and says:

Gradual improvement after severe attacks may continue for months; but whatever has not disappeared in from six to nine months, must be regarded as a permanent defect. The more quickly after an attack the improvement in motility appears, the more favorable is the progress.

We can easily understand why the general practitioner, influenced by these teachings, usually watches the case for from three to four months, and is satisfied with the improvements attained by that time. If the patient is then able to walk, he considers himself quite fortunate. If the contractures develop, he is put in the class of "chronic invalid" and is either allowed to remain in the house or sent to a "home for incurables." Many physicians are a little less cautious and do nothing to the paralyzed muscles for the first three months, waiting to see what improvement the patient will get from the medications, and only then is he sent to the neurologist and very seldom to the orthopedist. Of course, it is needless to repeat that, in many cases, the contractures are already present at that time.

The case which we have to report proves many of these statements and emphasizes new ones. We hope, therefore, that it will interest the readers to follow the details.

\section{CASE REPORT}

History.-M. W., man, aged 52, admitted to the Montefiore Hospital at the age of 27 , had a clear case of right sided hemiplegia with motor aphasia. He became paralyzed at the age of 26. As far as we can find in the history, the cause of the apoplexy was some trauma, sustained three weeks previous to the onset of unconsciousness. He was unconscious for twelve days, which indicates that the attack was quite severe. When he regained consciousness, he suffered severely from dizziness, vertigo and headaches, and was admitted to Mount Sinai Hospital. A decompression was done which relieved the symptoms but not the hemiplegia. He was admitted to the Montefiore Home and Hospital one year after the attack, unable to walk and presenting some contractures. (Probably nothing was done during that interval to prevent contractures.) He was put in the ward for chronic invalids and was confined to the chair and bed for twenty-one years, during which time he did not leave the home even once. Following the prevailing opinion, he was considered hopeless during all this time, and therefore received no treatments. He did not improve spontaneously, but, on the contrary, his paralyzed extremities became contracted. $\mathrm{He}$ did not regain his speech, but learned to write with the left hand so that he could make himself understood.

2. Dana, C. L.: Text Book of Nervous Diseases, Ed. 7, New York, William Wood \& Co., 1908, p. 467.

3. Church, Archibald, and Peterson, Frederick: Nervous and Mental Diseases, Ed. 8, Philadelphia, W. B. Saunders Company, 1914, p. 223 .

4. Starr, M. Allen: Organic and Functional Nervous Diseases, 5iladelphia, Lea \& Febiger, 1913, p. 495.

5. Curschmann, Hans: Text Book on Nervous Diseases, Burr's English Edition, Philadelphia, P. Blakiston's Son \& Co., 1915, ii,
667.681 . 